\title{
REVISTA DE SOCIOLOGIA
}

\section{INTERVENCION DEL PROFESOR}

\section{ALAIN TOURAINE *}

Nuestro siglo está llegando a su fin bajo el signo de dos fenómenos contrapuestos. Por un lado, las sociedades centrales definidas por su papel de autosustentadoras se están desmoronando o al menos dividiendo. Daniel Bell fue uno de los primeros en advertir sobre esta creciente oposición entre los ámbitos de la producción, el consumo y la política. En contraste con el primero, el segundo fenómeno es la movilización por parte de un creciente número de estados de sus sociedades, culturas y recursos nacionales; ello se realiza, o bien con el objeto de alcanzar la modernización, o de rechazarla como una invasión.

En los paises centrales, la pérdida de unificación, la separación entre los ámbitos mencionados anteriormente, es más importante que la movilización patrocinada por los gobiernos. En los países territoriales, sin embargo, muchos Estados han tratado de alcanzar una integración autoritaria y a menudo represiva a través de la re-interpretación de las tradiciones culturales. En ambos casos lo que llamamos sociedad desaparece; en el primero, porque la sociedad se rompe en astillas, en el segundo, porque es tragada por el Estado. Al describir estos dos procesos me gustaría explayarme en sus interrelaciones y luego examinar los intentos que se pueden observar en distintas partes del mundo para reconstruir las sociedades.

Lo que los sociólogos han llamado "una sociedad" no es sólo un territorio gobernado por un sistema de poder capaz de castigar las desviaciones de las normas institucionalizadas; en lugar de ello, una sociedad se refiere a un conjunto de correspondencias entre sistemas y actores, entre las normas institucionalizadas y la socialización de los individuos para quienes dichas normas, una vez internalizadas, se convierten en motivaciones. Esta correspondencia sólo existe cuando se reconoce un principio central de evaluación, lo que se aplica tanto a la organización de las actividades colectivas como al comportamiento individual. La ley divina o principio de las jerarquizaciones sociales o culturales, tales como la pureza, la conquista o las relaciones de parentesco, son a menudo, presentados como tal principio unificador. Las instituciones, así como los individuos, deberían ajustarse a esta ley superior.

Comúnmente, calificamos de modernas a las sociedades que confieren este papel central a la razón: ellas están claramente conscientes de sí mismas como sociedades. Para ellas el orden natural, la organización social y el comportamiento

* CADIS, EHESS, Paris, Francia. 


\section{Fronteras cuestionadas y solidaridades cambiantes}

individual son y deberían ser regidos por los mismos principios, es decir por aquellos basados en la razón. De acuerdo con ello, se piensa que el orden social constituye un lugar central en donde los individuos conviven en armonía con el orden natural y sus leyes. Las sociedades deberian hacer prevalecer el orden, la paz y la integración, manteniendo a raya el caos cósmico o controlando la paciencia individual. Sin embargo, la modernidad lleva en sí misma las fuerzas que rompen con este modelo y el pensamiento social siempre se ha organizado en torno al conflicto entre dos tendencias opuestas, porque la modernidad puede ser definida también como una creciente separación entre el mundo exterior y el mundo interior de la persona.

La separación cartesiana entre el espacio y el alma, entre la necesidad y la libertad ha continuado expandiéndose hasta el punto que muchos de nosotros denominamos a una sociedad como moderna cuando, a través de un mecanismo político, ésta combina la efectividad de la razón instrumental para controlar la naturaleza o sus propios instrumentos y la libertad de los individuos y de los grupos.

Mientras la sociedad pueda ser definida como una sociedad de producción basada en la división social del trabajo, en donde los individuos son sobre todo trabajadores, las tres esferas de la naturaleza, la sociedad y el individuo tienden a unificarse. Esta tendencia será mas fuerte que la creciente divergencia entre la racionalidad instrumental y la libertad personal. Sin embargo, con el advenimiento de la sociedad de consumo, el mercado prevalece por sobre la racionalización y la razón deja de ser un principio unificador.

Una sociedad como ésa emergió por primera vez en Estados Unidos, después de la victoria simbólica de la General Motors sobre la Ford luego de la Primera Guerra Mundial. Desde entonces no ha habido forma de detener las crecientes divergencias entre la razón -basada más en la tecnología que en una visión racionalista del mundo y concebida como una estrategia- $y$ la ahora universal lucha por la libertad y la identidad. Esta ruptura entre el universo de los significados y el universo de la ciencia, la mercancía, la información y los flujos económicos, significa que el individuo como tal debe ser redefinido; en lugar de referirse a la razón y sus leyes y con el objeto de afirmarse a sí mismo, el individuo se torna auto referente, se define a sí mismo como una combinación, en su interior, de la razón, de la herencia cultural y de un proyecto individual de vida.

En la medida en que las grandes ideologías han desaparecido (lo que estuvo muy bien) y tal como Jean Francois Lyotard to ha señalado, los individuos intentan, cada vez más, hacer de sus propias vidas una historia personal -para usar la frase de Mclntire. Estamos presenciando una creciente separación entre la acción estratégica y (LABEN WELT). Me gustaría agregar rápidamente que deberíamos evitar abanderizarnos con alguna de ellas. En efecto, estamos enfrentado una doble amenaza. Por un lado, la dominación del mercado y de la tecnología está cau- 


\section{REVISTADE SOCIOLOGIA}

sando una exclusión masiva y produce un conformismo destructivo. Por otro lado, los gobiernos y los nuevos movimientos comunitarios están usando la fuerza para imponer una dictadura basada en la pureza moral, religiosa, nacional o étnica.

La obsesión, por un lado, por la competencia y la obtención de beneficios económicos y, por el otro, por la identidad, son fuerzas opuestas que han destruido lo que solía denominarse sociedad. Esta última no resucitará, al menos no en las formas conocidas. En estos últimos años del siglo veinte, el mundo aparece como una red de consumo y de comunicación, carreteras que atraviesan los ghettos, separándolos unos de otros; estos ghettos, o bien son gobernados con mano dura o abandonados a la asistencia social. En todas partes del mundo las tribus y el mercado están crecientemente desconectados entre sí, la obsesión por las identidades prevalece no sólo entre los gobiernos fundamentalistas del Tercer Mundo o entre los movimientos nacionalistas intolerantes, también puede ser detectada en formas extremas de multiculturalismo en el norte. Mientras tanto el mercado, su información, imágenes y productos, se diseminan por todo el planeta, desde China a Argentina.

Este quiebre de la sociedad no es sólo un signo del fin de un ideal, tiene también un impacto en todas las instituciones. Entre una economía cada vez mas abierta y culturas cada vez mas cerradas, no existe ya ninguna mediación social, política o institucional. El pensamiento post moderno ha ejercido una amplia influencia porque apoya lo que los otros tratan de evitar y niega toda referencia histórica a la cultura. Al abrazar el multiculturalismo, el pensamiento post-moderno acepta la plena libertad para inventar y reinterpretar las culturas mientras reconoce la existencia de redes y movimientos transculturales; así, acepta la yuxtaposición entre el mercado y las tribus. Todo esto puede ejercer una atracción estética pero, a nivel social, refleja algo mucho más tedioso.

Los flujos y signos universales no tienen capacidad de socializar a los individuos. Y lo que es más importante, este universo, lejos de ser un lugar en donde prevalece la racionalidad favorable a todos, es dominado por actores, intereses y estrategias financieras. La victoria de la economía de mercado produce exclusión, aún más cuando el individualismo triunfante hace de aquellos que fracasan responsables de sus fracasos; simplemente no supieron como jugar el juego. Por otro lado, la obsesión por la identidad no estimula la creatividad y la diversidad cultural, en lugar de ello está llevando hacia un control político autoritario sobre la cultura reinterpretada. Al dejar de ser fuentes vivas de producción de significados, las culturas se convierten en tradiciones intangibles para legitimar el poder autoritario.

Finalmente, cómo podemos dejar de ver que en el mundo reducido de la yuxtaposición del mercado y las tribus las fuerzas del mercado comandan el lugar de las tribus en un sistema de relaciones jerárquicas: las más inferiores son aquellas 


\section{Fronteras cuestionadas y solidaridades cambiantes}

que rechazan en forma más activa la dominación del mercado. Esto genera una exclusión y segregación aún más complejas.

Ahora debo considerar un problema difícil que debería agregarse a esta descripción del mundo unificado a la vez que dividido, prácticamente deprivado de gobiernos, en donde casi no existen los medios para manejar las interacciones entre los objetos universales y las subjetividades universales. ¿Deberiamos apelar al diálogo intercultural y al refuerzo de las organizaciones interculturales?. Siendo esto muy importante, tal llamado sería en vano. Sin embargo, se han realizado esfuerzos bastante reales para reconstruir la vida social en la sociedad.

Permítanme mencionar algunos de los más importantes. Un medio ambientalismo, que es una ecología políticamente comprometida, representa un intento de reconciliar la razón instrumental con las identidades. Pero no queda claro qué dirección tomará el ambientalismo. Esta corriente de pensamiento parece vacilar constantemente entre el retorno anti-moderno a la naturaleza y un intento muy moderno -lo cual me parece muy válido- de reconciliar la economía con el respeto por la diversidad cultural y la diversidad biológica. También difiere en forma significativa de la definición quasi clásica de la modernización entendida como una autonomía relativamente creciente y una diferenciación interna de cada subsistema social. Al abogar por la diversidad en un mundo globalizado, ¿no estamos abordado una dificultad central?, es decir, ¿cómo lograr la combinación necesaria entre el uno y los muchos?. Esta combinación no puede ser alcanzada apelando a un principio superior. Dios solía ser tanto la razón como la voluntad y la nación encarnaba la soberanía popular y representaba una cultura común en la historia. Ya no existe un principio unificador activo toda vez que una ruptura total ha separado al universo de razones instrumentales del universo de las identidades.

Las Weltanschaung* unificadoras son poco más que ideologías estatales que destruyen la razón universal así como la tradición cultural; su único propósito es reforzar un poder orientado al totalitarismo. No es posible combinar la razón instrumental y la identidad cultural y almacenarlas, excepto a nivel del actor individual, porque las personas combinan distintos tipos de fines y medios, en tanto que es imposible combinar dos visiones del mundo o dos sistemas institucionales. De acuerdo a S. Packard, que demostró que el recurso de la imaginación y del juego ayuda a los niños a pasar a un nivel más elevado de desarrollo intelectual, tal como lo define Piaget, debemos abandonar la creencia en un solo modelo racional de organización social.

Tal como lo demostraron hace mucho tiempo los sociólogos organizacionales, la organización de la sociedad, en lugar de ser un conjunto de normas técnicas presumiblemente racionales, es siempre el resultado de procesos políticos. Pero ¿quién es este individuo que lucha por reunificar un mundo dividido dentro de sí mismo y por qué esta tratando de hacerlo? El individuo busca la individuación y 


\section{REVISTA DE SOCIOLOGIA}

por ende su libertad y lo que denomino subjetivación, que es un deseo consciente de individuación. En otras palabras, el individuo lucha por evitar que se le reduzca, ya sea a un conjunto de roles económicos y sociales o a un miembro de una comunidad cultural; en lugar de ello, él esta tratando de construir una historia de vida, tal como lo mencioné anteriormente.

El sujeto es la determinación del individuo de ser un actor, es decir, de modificar su medio de tal modo de aumentar su autonomía, dar continuidad a su experiencia y alcanzar la individuación. El sujeto no es una persona, un ego; se define a sí mismo en la lucha por combinar una racionalidad que lo individualiza ante su comunidad y una particularidad cultural que lo protege de la cultura de masas. El sujeto no existe por sí y fuera de sí mismo, debe ser protegido y apoyado por las instituciones; ese es el significado real de la democracia hoy en dia.

La democracia ya no apela a la igualdad de derechos en contra de la desigualdad social: ahora lucha en contra de la desigualdad, no porque todos somos parecidos sino porque somos distintos. Es la forma de gobierno la que protege la diversidad y requiere de la solidaridad, ya que cada persona debe reconocer el derecho de cada uno a convertirse en sujeto. La libertad, la diversidad y la solidaridad, son los tres principios que mejor definen a la democracia; ésta es una forma contemporánea de la definición más general pero más clásica de la democracia en términos de la libertad, la igualdad y la fraternidad.

Por estas razones, la noción de sujeto no lleva de ninguna manera a un individualismo indiferente a los problemas de la vida en sociedad. Al contrario, el recurrir a esta noción aniquila una visión puramente sociológica de la sociedad en términos de necesidades, funciones o estructuras. Una sociedad no es un sistema sino un campo en donde los actores, orientados por sus deseos de subjetivación así como por la racionalidad instrumental, luchan en contra de las racionalidades internas del poder y organizan la vida colectiva respetando los derechos individuales fundamentales.

La reconstrucción social bajo las condiciones individuales y colectivas señaladas, implica abandonar un principio clave de la movilización occidental, cual es la ruptura entre tradiciones y modernidad. La construcción del sujeto requiere, como dice Marcel Mauss, juntar to que ha sido separado, reconciliar lo que ha sido considerado contradictorio y recomponer el mundo. El reconocer al otro significa algo más que aceptar sus diferencias, significa descubrir en él o en ella la lucha por combinar racionalidad y cultura. La unidad y la diversidad no deberían ser separadas, pero la meta que todos compartimos puede ser alcanzada solo de manera diferente por cada individuo y cada sociedad.

El pesimismo de fines del siglo $X X$ visualiza la oposición entre las sociedades centrales -sin poder y en proceso de desintegración- y las sociedades periféricas que son movilizadas por líderes autoritarios. Pero yo considero una hipótesis más 


\section{Fronteras cuestionadas y solidaridades cambiantes}

optimista: la sociedad puede ser reconstruida en torno a las ideas del sujeto y de la democracia.

Sin embargo, hasta ahora sólo he mencionado procesos que se aplican principalmente a las sociedades centrales que se están desintegrando. Es necesario agregar que las ideas del sujeto y la democracia revisten otras formas igualmente importantes, en las numerosas sociedades periféricas en donde los sistemas autoritarios detentan el poder. Más que el progreso y la subjetivación, las prioridades en la periferia son la creación de una sociedad politica independiente del Estado y el logro del reconocimiento de los derechos de las minorías. En la situación de dependencia, cambiar la forma poltitica de gobierno es clave para la libertad individual, mientras que en otras partes, la libertad individual y la voluntad del individuo de ser libre, constituyen las bases más sólidas de la democracia.

De acuerdo con numerosos observadores del mundo contemporáneo, en esta compleja sociedad en rápido cambio, ya no existe un problema central como el imaginado por todos aquellos que en la sociedad industrial visualizaban las relaciones de clase como elementos determinantes.

Este análisis que he presentado en forma resumida, se basa, por el contrario, en la idea de que los problemas sociales y polticos del mundo contemporáneo giran en torno a un problema más central que la lucha de clases entre el capital y el trabajo. Este problema tiene que ver con el conflicto entre la unidad de la actividad globalizada y la multiplicidad de la identidad cultural individual o colectiva. Los debates más interesantes del pensamiento social contemporáneo se desarrollan en torno a estos temas. Mientras que algunas teorías abogan por un multiculturalismo extremo, otras permanecen ligadas al efecto unificador de tener tantas personas como sea posible participando de las mismas nociones y de las mismas leyes.

Sin embargo, las teorías más elaboradas, como es el caso de Jurgen Habermas, han ligado el reconocimiento del otro con todas sus diferencias al redescubrimiento en el otro de una relación con la universalidad que tiene que ver no sólo con la ciencia sino que también con el juicio moral o estético. Pero ya no vivimos er un universalismo tan substantivo, nuestro racionalismo es estratégico, es instrumental. Por consiguiente, nuestra identidad cultural, tal como lo he señalado, se basa cada vez más en el status adquirido, en la nacionalidad, el género o la religión. Como consecuencia de ello, la subjetivación es la única forma de combinar la racionalidad y la identidad. Vale la pena señalar que los debates a los cuales me he referido proporcionan el marco de referencia más adecuado para comprender una amplia gama de problemas sociales y poltiticos concretos.

Desde mi punto de vista, lo más importante es que países como Estados Unidos - India están mucho más conscientes de problemas de este tipo que los países de Europa o de América Latina. Puede que por esta razón los movimientos sociales y 


\section{REVISTA DE SOCIOLOGIA}

las campañas de opinión pública sean mucho más activas que en las sociedades europeas. Estas últimas tienen dificultades para alejarse de la filosofía racional de la lluminación y su modelo de democracia republicana, o bien están entregados a un laissez faire económico y cultural que genera tensiones a la vez que no acepta mecanismos para resolverlas. Solo a través de intercambios alrededor de todo el planeta nos arreglaremos, cada uno de nosotros a nuestra manera, para reconstruir la unidad de nuestras experiencias de vida. Gracias. 